\title{
Computed Tomography - its Develop- ment, Principle and Image Artifacts
}

\author{
Teodor Tóth *, Radovan Hudák
}

${ }^{1}$ Technical university of Košice, Faculty of Mechanical Engineering, Department of Biomedical Engineering and measurement, Košice

\section{BIOGRAPHICAL NOTES}

Ing. Teodor Tóth, PhD., received M.S. degree in mechanical engineering from Technical University of Košice, Slovakia in 2001 and PhD. degree in Biomedical Engineering from Technical University of Košice, Slovakia in 2009. He is a researcher of Department of the Biomedical Engineering and Measurement at the Faculty of Mechanical engineering at the Technical University of Košice, Slovakia. His research interests include biomedical engineering, computed tomography and measurement. He is co-author of 5 books and more than 70 journal and conference papers.

doc. Ing. Radovan Hudák, PdD. was born in 1976 in Košice, Slovakia. He received his MS and PhD degree in biomedical engineering at Technical University in Košice in 2000 and 2008. Today Mr. Hudák is an associate professor and head of prosthetics and orthotics study program and head of Biomedical Engineering Division at the Department of Biomedical Engineering, Automation and Measurement, Technical University of Košice. His research interests include additive manufacturing in medicine, medical thermography and industrial thermography and human biomechanics. Since 2004 he was technical assistant at the Center of Refractive Surgery in Košice. Mr. Hudák has more than 100 publications in home and foreign journals. He is co-author of 5 monographies and 10 books.

\section{KEY WORDS}

Computed tomography, measurement, artifacts, metrology.

\section{ABSTRACT}

Paper deals with medical and industrial tomography and describes they development, utilization and their basic functions and design principles. During sensing of object (patient) may occur artifacts caused by scanning object (body movement, implants, beam hardening). The paper describe the most frequently artifacts and compare the parameters of medical and industrial CT machines.

\section{Introduction}

CT (Computed Tomography) is non-invasive diagnostic method, which has begun to apply in medicine since the beginning of the 70 s and it has progressively become an irrecoverable part of the complex of imaging methods used by modern medicine. CT scanning made a remarkable effect on medical practise and diagnosis. The main principle of $\mathrm{CT}$ is based on attenuating of $\mathrm{X}$-ray radiation beam passing object as in conventional X-ray examination. Artifacts can significantly interfere the quality of CT images to such an extent that they are useless for diagnosis. For the needs of optimizing image quality it is necessary to understand why artifacts arise and how is it possible to prevent from them. In CT the notion artifact is applied on any systematic non-conformity between CT numbers in a reconstructed image and real coefficients 
of attenuating of scanned object [1].

\section{Development and principle of medical CT}

In October 1, 1971 CT examination was for the first time carried out in 41-year-old female patient and the frontal lobe tumor was discovered. The scanning of the patient lasted 15 hours and the CT machine developed by sir Godfrey Neobold Hounsfield (Nobel Prize laureate) in EMI company (Electrical and Musical Industries) in London was used. The musical industry EMI after the success of the Beatles recordings invested in a new product. For the first time in the history of medical radiology doctors were able to obtain the high quality images of cross section of the internal parts of the body. Since then the explosive technical sophistication has dramatically developed CT scan techniques and with the new research possibilities this development is being in progress even today [2].

1 st generation of CT scanner used by Hounsfield in his original experiment consisted of parallel beam geometry, in which numerous measurings of permeated X-ray beam were carried out with the help of single suppression narrow pencil $X$-ray beam and detector. The beam was moved in linear motion over patient in order to obtain the projection profile. Subsequently the source and the detector rotated around the patient by aproximately $1^{\circ}$ and so another projection profile was taken. This translational-rotational scanning motion was repeated until the source and the detector turned around by $180^{\circ}$ [3]. The mathematical model of $X$-ray CT transmission is described below.

The slow speed image data acquisition (approximately 5 min for each image) meant the restriction of scanning for moving artifacts connected with longlasting scanning only on head. In order to overcome these time restrictions 2 nd generation of CT scanners which used a narrow fan-shaped beam and more detectors was developed. Although those scanners also used the translationalrotational moving the scanning time was reduced to 30 seconds because of the narrow fan-shaped $X$-ray beam and the linear series of detectors which facilitated bigger rotational acquisitions. In 1976 3rd generation of CT scanners which used fanshaped beam configuration and rotating series of detectors was launched. In this generation fanshaped X-ray beam together with the curved series of hundreds of detectors rotated by $360^{\circ}$ around the patient.

3rd generation of CT scanners enabled only 1 -second acquisition. Consequently 4th generation of CT scanners used the rotating fan-shaped non-stationary series of detectors consisting of 600-4800 independent detectors arranged in a circular configuration around the patient was developed. The scanning times of 4th generation were similar to 3rd generation scanning times.

The requirement for faster scanning heavily influenced the further development of $\mathrm{CT}$ technology in order to obtain volumetric data for 3D displaying and multiphase acquisition of images. It was enabled by the revolutionary development of slip-ring technology in 1990 which allowed Xray source to rotate around the patient without reverse rotation (which was inevitable in conventional CT scanners) [4].

In combination with high-energy X-ray lamp, more efficient computers and more sophisticated displaying algorithm, the slip-ring technique enabled spiral CT scanning. This consists of continually activated X-ray source and continual movement of top board of the table through the gantry (a part of CT machine, a ring composed of a system of detectors and rotating $X$-ray) which results in volumetric acquisition. SSCT (Spiral Scan CT) machines enabled faster and continual scan technology to obtain numerous cross cuts and volumetric data. The significant parameter for spiral scan characterization is pitchp. According to IEC specification in $2002 p$ is determined: $p=$ movement of table in one rotation / total thickness of beam suppression [5].

In 1998 the multi-slice spiral CT technology was set up which enhanced CT applications. Although MSCT (Multi-slice Spiral Compute Tomography) made use of the same slip-ring technology as SSCT, it provided a unique advantage in terms of increased movement of the table on rotation resulting in enlarged thickness of fan-shaped beam suppression based on width configuration of series of detectors. It is interesting that CT scanners were considered as mono-slice technique despite the fact that the first CT scanners were de facto twoslice scanners [6]. Fast development of multi-slice technology from 2000 to 2007 brought 2, 4, 8, 16, 40, 64, 256 and 320-slice CT scanners. Looking at the numbers of slices of MSCT and a year of their operation it is obvious that the number of slices ex 
ponentially increased as a time parameter roughly twice each year which is in compliance with Moore Laws of Electronics [5].

Further development was different. In 2005 the first dual-source CT scanner was launched (Fig. 1). The main benefit of DSCT (Dual Source Computed Tomography) was the scanning of the heart with improved temporal distinction. It provides the temporal distinction of one quarter of the rotation time of the gantry which is independed of the heart action and it does not need multisegmental reconstruction techniques. Except heart examination this scanner is a contribution also for general radiology. The acquisition of dual energy is the revolutionary benefit. Both X-ray lamps can operate with either various settings $\mathrm{kV}$ or various prior filtration. Among potential applications of CT examination with dual energy there is the tissue characterization, calcium quantification and the quantification of local blood volume in contrast images [6].

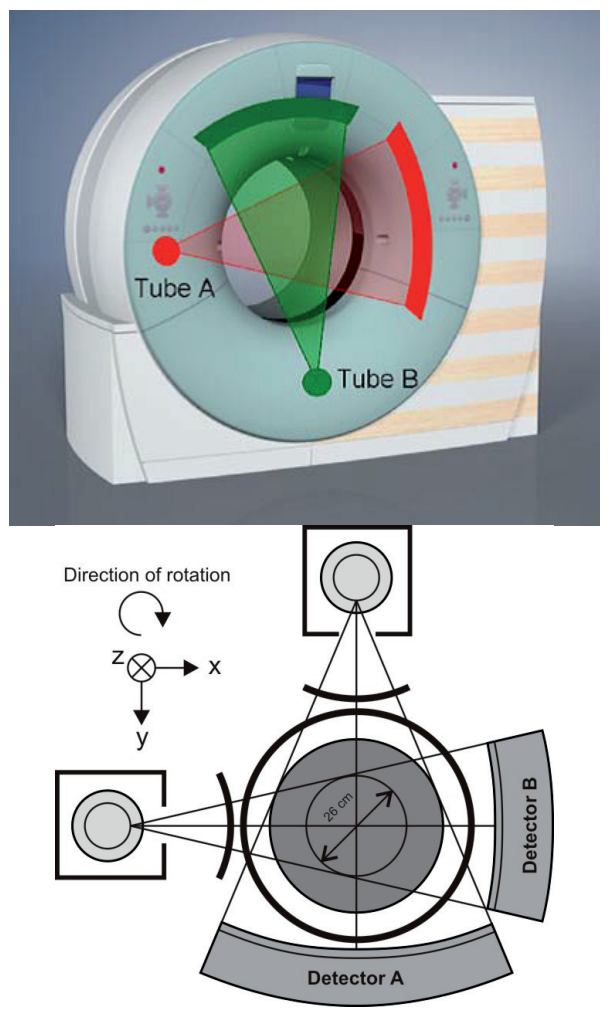

Fig. 1: DSCT scanner. A schematic illustration of DSCT machine using two X-ray lamps and two series of detectors mutually placed in $90^{\circ}$. This type of scanner provides the temporal distinction equal to a quarter of rotating time of gantry independent of the heart ac- tion. In technical realization first detector (a) covers tho whole scan FOV (field of view) with average $50 \mathrm{~cm}$ and second detector (b) has got smaller FOV [7].

By means of modern MSCT scanners it is possible to display the whole human body during the comfortable breath holding. Improved and faster displaying algorithms, improved capacity of data storage and higher quality of 3D displaying significantly affected hardware development. Obviously usage of MSCT scanners leads to the increased productivity of CT and multi-slice examinations are carried out with more complicated protocols than CT examinations with SSCT scanners [8]. Further development of CT scanning should provide information of 4D scanning, what is the dynamic volume scanning. CT scanners with conical beam have even today the capacity for 3D displaying of larger volumes with isotropic distinction and they have a potential for 4D displaying because they are capable to obtain data from large volumes during one rotation both X-ray lamp - detector [9]. At present Toshiba and Siemens companies are imposing machines focused on this target. Toshiba launched 320-slice scanner which enables to examine all organs during one rotation. Siemens introduced 128-slice scanner with dynamic spiral shuttle mode which enables to gain 4D data from large volumes. Figure 2 demonstrates the example of perfusion scan of the whole brain. Perfusion scan has been possible only in one-slice so far.

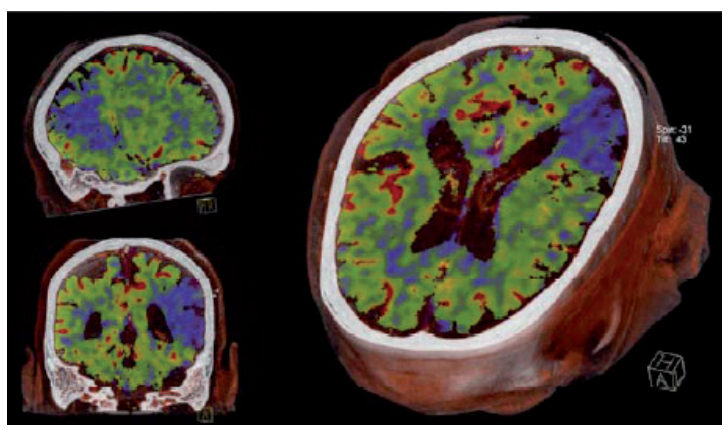

Fig. 2: Perfusion scan of the whole brain on the device Siemens SOMATOM Definition AS+

Configuration of detectors $128 \times 0,6 \mathrm{~mm}$ and detector coverage $38,4 \mathrm{~mm}$ was carried out for perfusion scan of the whole brain in special spiral shuttle mode which uses sinusoidal movement of patient's bed through the whole brain within 
30sec. [5].

Prototype CT scanners use the technology of flat panel detectors originally used for conventional catheterization angiography. Their excellent spatial distinction as a consequence of small size of detector pixels predetermines them for clinical applications from ultra-high distinctive bone displaying through dynamic CT angiography study to functional examinations [10].

\section{Development and Principle of Industrial CT}

Since 1980, CT became popular for material analysis and non-destructive testing: e.g. for observing the inner structure of materials (e.g. fiberreinforced plastics) and detecting material defects. More recently, CT technology entered the application field of dimensional metrology, as an alternative to tactile or optical 3D coordinate measuring machines, measuring arms, fringe projection systems, etc. In 2005 was exhibited at the Control Fair in Germany the 1st dedicated dimensional CT machine. So far, dimensional CT metrology is the only technology able to measure as well the inner as the outer geometry of a component without need to cut it through and destroy it. As such, it is the only technology for industrial quality control of workpieces having non-accessible internal features (e.g. components produced by additive manufacturing) or multi-material components (e.g. $2 \mathrm{~K}$ injection molded plastic parts or plastic parts with metallic inserts). [18]

The measurement principle is same as in medical tomographs but the construction of the measuring machine is different. In Figure 3 are shown two basic principles. In the case of industrial tomograph, the measured object rotated around its axis and the X-ray source and the detector is not moving.

\section{FLAT PANEL DETECTOR}

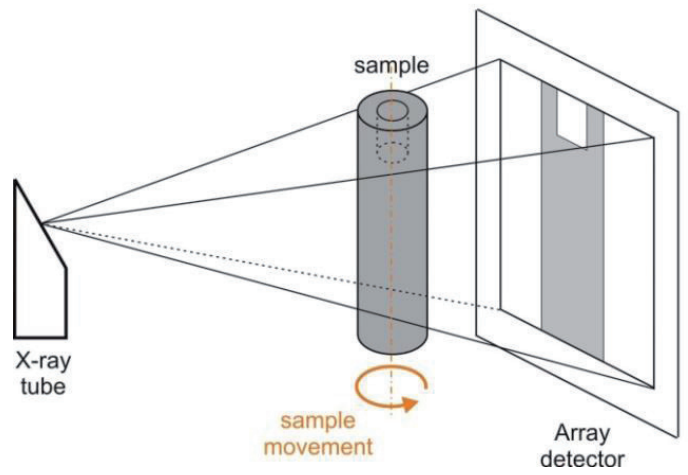

LINE DETECTOR

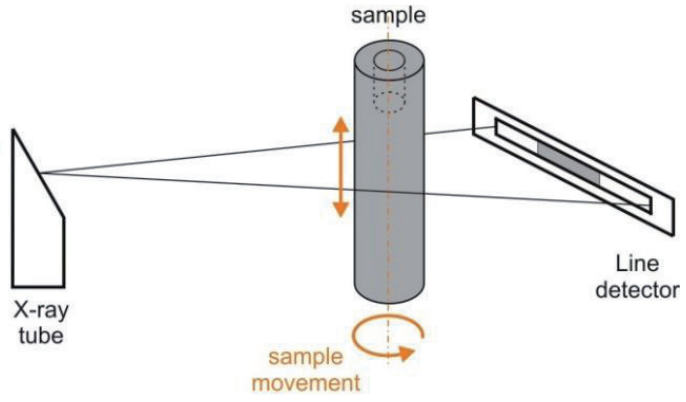

Fig. 3: Construction of tomograph with array (2D) detector (left) and line (1D) detector (right) and sample movements.

\section{Reconstruction of Three-dimensional Object}

The reconstruction of three-dimensional objects such as the simple key shown in Fig. 4 by the metrotomography is based upon using $X$-ray computed tomography (x-ray $C T$ ) to acquire complete information on the distribution of material in each object. The underlying physics and mathematics of this process will be briefly described in this section.

The X-ray photon density that emerges when a narrow bean of monochromatic $X$-rays with energy E (Joules) and intensity 10 (Joules/sec- $\mathrm{cm}^{2}$ ), passes through a homogeneous material of density $\eta\left(\mathrm{g} / \mathrm{cm}^{3}\right)$ and atomic number $Z$ can be expressed as:

$$
\begin{aligned}
& I(x)=I_{0} \exp [-\beta(\eta, Z, E) x]= \\
& =I_{0} \exp [-\beta x]
\end{aligned}
$$

where: $\beta_{0}$ is the $X$-ray attenuation coefficient $(1 / \mathrm{cm})$. If we further assume for an inhomogeneous material that the attenuation coefficient is a space varying function, and the material can be represented by thin slabs, then adding up (or integrating the attenuation in each slab) we find that in one dimension the total attenuation by the material from $\mathrm{x}=0$ to $\mathrm{x}=\mathrm{L}$ is given by:

$$
I(x=L)=I_{0} \exp \left[-\int_{0}^{L} \beta(x) d x\right]
$$

Further, if we now scan the $X$-ray beam across the material in the $y$-direction we obtain an intensity profile for the object as:

$$
I(y)=I_{0} \exp \left[-\int_{0}^{L} \beta(x, y) d x\right]
$$


In X-ray CT imaging the X-ray source and detection equipment is designed to collect such intensity profiles over cross sections of three-dimensional objects. Each slice of the object presents a two-dimensional X-ray attenuation map - $\beta(x, y)$ - to the beam with a thickness defined by the dimensions of the detector.

We need to keep track of the relationship between the fixed, laboratory frame of reference for the object $(\mathrm{x}, \mathrm{y})$ and the rotating frame of reference for the $\mathrm{X}$-ray system $\left(\mathrm{x}^{\prime}, \mathrm{y}^{\prime}\right)$, which is a function of the rotation angle $\theta$ is given by the simple matrix equation:

$\left[\begin{array}{l}x^{\prime} \\ y^{\prime}\end{array}\right]=\left[\begin{array}{cc}x \cos \theta & y \sin \theta \\ -x \sin \theta & y \cos \theta\end{array}\right]$

Then, as illustrated in Figure 4, a simple plot of the $X$-ray intensity as the $X$-ray beam scans across the key as the angle $\theta$ can be written as:

$$
I_{\theta}\left(x^{\prime}\right)=I_{0} \exp \left(-\int_{y^{\prime}=A}^{y^{\prime}=B} \beta(x, y) d y^{\prime}\right)
$$

The detected data then consists of many two-dimensional scans or projections, $\mathrm{P}_{\theta}\left(\mathrm{x}^{\prime}\right)$, each taken at a different angle (see Figure 4):

$$
\begin{aligned}
& P_{\theta}\left(x^{\prime}=p\right)=-\ln \left\{\frac{I_{0}\left(x^{\prime}=p\right)}{I_{O}}\right\}= \\
& =\int_{\text {Line } A B} \beta(x, y) d y^{\prime}
\end{aligned}
$$

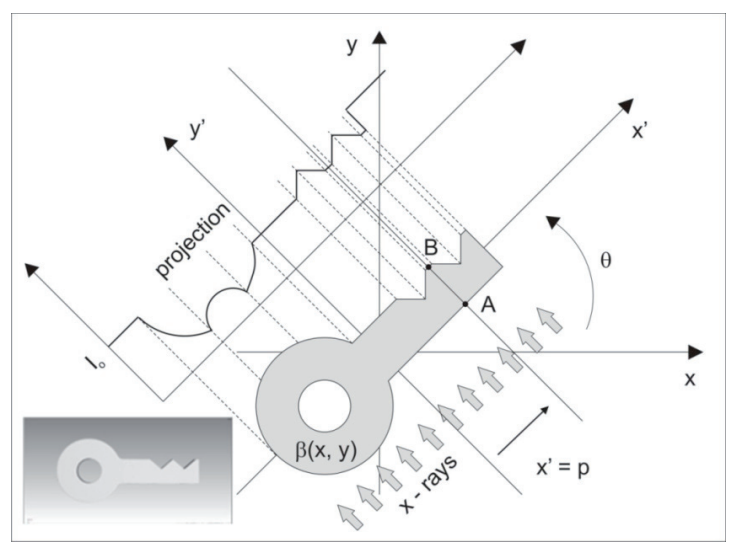

Fig. 4: X-ray beam intensity profile of a key with X-ray attenuation $\theta(x, y)$ along the $x^{\prime}$ axis for the viewing angle $\theta$. From the profile the projection $P_{\theta}\left(x^{\prime}\right)$ can be constructed as a formal Radon transform.

By rotating this projection through 180 degrees we collect information on the absorption of X-rays from all angles.

Finally, the overall relationship between the projection of the absorbed X-ray intensity is contained in the complete integration over the physical extent of the object. This representation has the mathematical form of the Radon transformation [17]:

$$
\begin{aligned}
& P_{\theta}\left(x^{\prime}\right)=\iint_{\text {objekt }} \beta(x, y) \delta\left(x^{\prime}-p\right) d x d y \equiv \\
& \equiv R(p, \theta)[\beta(x, y)]
\end{aligned}
$$

Inversion of the Radon transform, by simple back projection or some form of algebraic reconstruction gives the needed information, the cross section of the $\mathrm{X}$-ray absorption $\beta(x, y)$.

\section{Artifacts of CT Displaying}

There are many reasons for CT artifacts formation. Physical artifacts come from physical process involved in acquisition of CT data. Artifacts caused by patient are induced by moving of patient or by the presence of metal objects on patient. Artifacts caused by scanner are the consequence of imperfection in scanner function. Artifacts of spiral and multi-slice technique are caused by the display reconstruction process. Construction elements incorporated into existing CT scanners minimalize such artifacts which can sometimes be partly corrected by the software of scanner.

In spite of this in many cases carful positioning of patient and optimal parameter selection of scanning are the most significant factors to prevent from CT artifacts. CT image in its nature is more prone to artifacts than conventional $X$-ray image, because the image is reconstructed of millions of independet detector measurements. The reconstruction technique assumes that all the measurements are correct so any defective measurements are normally reflected as an error in reconstructed image $[1,11]$.

\subsection{Artifacts from metal}

The presence of metal objects in scanned area can cause strong striped artifacts. The density of metal is out of normal extent of the computer so that partial profiles of weakness are obtained. Additional artifacts as a result of beam hardening, partial volume and aliasing are a serious problem when scanning very dense objects.

Prevent metal artifacts service. Before scanning 
patients are asked to remove all removable metal objects such as jewels. It is possible to avoid unremovable objects such as dental fillings, prosthetic devices and surgical clips by lean of gantry so that metal parts do not interfere scanned part of the body. If impossible to modify required scanned part in order to avoid metal objects the technical change mainly increasing in kilovolts can help the beam to penetrate through some objects more efficiently. The ratio of artifact partial volume is reduced by using of thinner cuts.

Software correction of metal artifacts. The striping caused by exceeding extent can be largely reduced by using of special software. Producers use various interpolating techniques due to replacing figures of excessive extent in profiles of weakness. Effectiveness of one of these techniques is viewed in figure 5. However the usefulness of the cutdown metal artifact software is sometimes restricted because although striped artifacts are removed from metal implants there is a loss of details around interface metal - tissue what is often the area of diagnosis interest. The software for correction of beam hardening should be used when scanning metal objects to minimalize additional artifacts as a result of beam hardening [12].

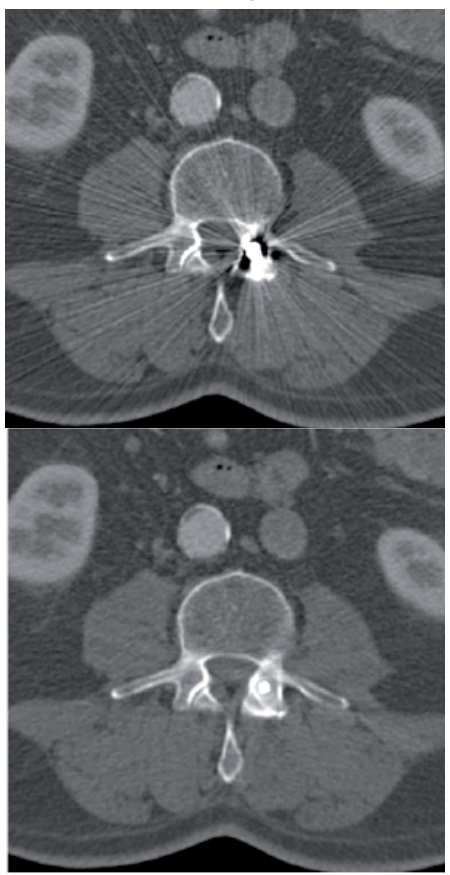

Fig. 5: CT images of patient with metal implants in spine. Left displaying without correction and right with metal artifact cutdown [4]

\subsection{Patient's moving}

Patient's moving can cause artifacts of wrong registration which eventually occur as shades or stripes in displayed image (Figure 6).

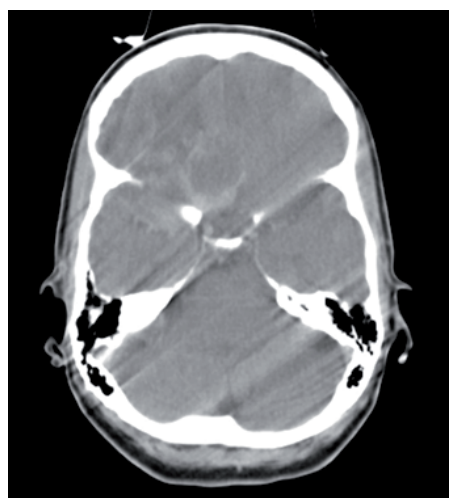

Fig. 6: CT image of head showing moving artifacts [11].

Steps can be carried out to prevent from free movement though during scanning it is sometimes impossible to avoid free movement. However additional devices exist for some scanners designed in order to minimalize these artifacts.

Prevent moving artifacts service. Using positioning device is adequate to prevent from unwanted moving in most patients. In spite of this in some cases (e.g. children) it is inevitable to immobilize patients via sedation. Using the shortest scan time helps minimalize these artifacts when scanning the area prone to move. It is possible to minimalize respiratory movement if patient is able to hold breath while scanning. Sensitivity of image on moving artifacts depends on moving orientation. That's why it is better if starting and final position of X-ray lamp is in direction with primary movement, e.g. vertical above or under the patient when scanning thorax. Special mode of body scanning unlike head scanning mode can automatically have added a reduction of moving artifacts in displaying.

Built-in functions for minimizing of moving artifacts. Producers minimalize moving artifacts by using of excessive and partial scanning mode, software correction and cardial gating (see below).

Excessive and partial scanning mode: Maximum discrepancies in detector measurements occur between projections obtained in starting and final $360^{\circ}$ scan.

Some types of scanners use excessive scanning 
mode for axial scans where $10 \%$ is added to standard $360^{\circ}$ scan. Repeated projections are averaged what helps cutdown moving artifacts.

Using partial scanning mode is also available for cutdown moving artifacts though it can result in a weaker distinction. $[15,16]$

\section{$\underline{5.3 \text { Partial projections }}$}

If a part of patient's body lies out of scanned field of view the computer has partial information about this part and striped and shade artifacts occur. This is viewed in figure 7 which shows a patient scanned with upper limbs placed along the body instead of raising them out of scanning extent. If upper limbs are placed out of scanned field of view they are not present in the image but their presence in some projection when scanning leads to such serious artifacts in the image that significantly degrade their using. Similar effects can be evoked by dense objects such as intravenous tube containing contrast medium lying out of scanned field. Blocking reference canals on the side of beam detectors can also interfere with normalization of data and cause striped artifacts [11].

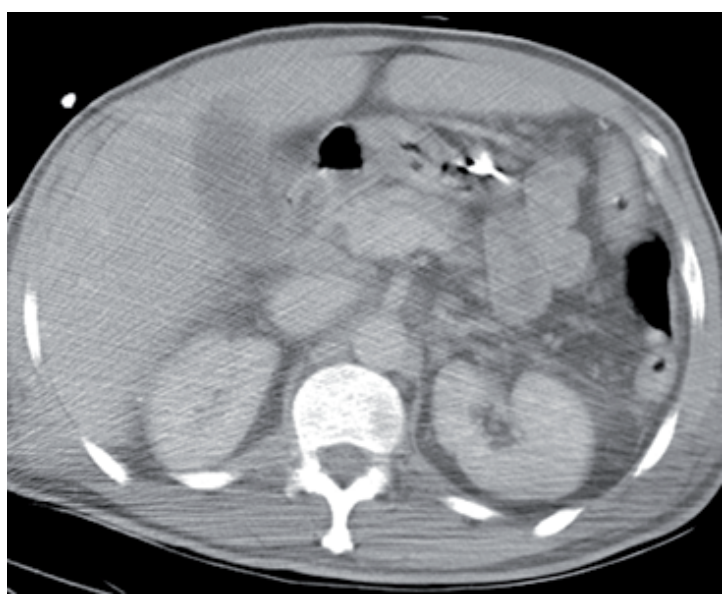

Fig. 7: CT image with striped artifacts. CT image of body of patient with upper limbs along the body but out of scanned area what causes striped artifacts (Radiology Department).

In order to prevent from artifacts due to partial projections it is inevitable to position patient so that any part of the body does not lie out of the scanned field. Scanners designed for planning radiation therapy have larger holes and larger scanned field and they allow greater extent in patient positioning. It also allows to scan extremely enormous patients who cannot fit in the hole of normal scan- ners. Some producers monitor reference data canals to obtain discrepancies and if these reference data seem to be suspicious they avoid using them [11].

\section{Comparison of Medical and Industrial Tomo- graphs}

From the text above are evident construction differences between two types of tomographs. The line detector industrial tomograph construction and sensing principle is closer to medical tomograph than the industrial tomograph with plane panel detector. The two types of tomographs are using different power in outputs. In the next table (Table 1) are presented selected parameters for medical and industrial tomograph Zeiss Metrotom 1500.

Table 1: Parameters for selected CT scanners [19, 22, 23]

\begin{tabular}{|c|c|c|c|c|}
\hline & $\begin{array}{l}\text { ZEISS } \\
\text { Metrotom } \\
15001 \text { Mpix }\end{array}$ & $\begin{array}{l}\text { ZEISS } \\
\text { Metrotom } \\
1500 \text { 2Mpix }\end{array}$ & $\begin{array}{l}\text { Siemens } \\
\text { SOMAT } \\
\text { force }\end{array}$ & $\begin{array}{l}\text { GE } \\
\text { Discovery } \\
\text { CT750 HD }\end{array}$ \\
\hline $\begin{array}{l}\text { Detector } \\
\text { resolution } \\
\text { (pixel) }\end{array}$ & $\begin{array}{l}1024 x \\
10124\end{array}$ & $\begin{array}{l}2048 x \\
2048\end{array}$ & $\begin{array}{l}2 \times 96 / \\
\text { detector }\end{array}$ & \\
\hline Detector type & Plane & Plane & Line & Line \\
\hline $\begin{array}{l}\text { Number of } \\
\text { detectors }\end{array}$ & 1 & 1 & 2 & 1 \\
\hline $\begin{array}{l}\text { Generator } \\
\text { power [W] }\end{array}$ & 225 & 225 & $2 \times 120 k$ & $100 \mathrm{k}$ \\
\hline Voltage [kV] & 225 & 225 & 150 & 140 \\
\hline Current [mA] & 1 & 1 & 800 & 835 \\
\hline $\begin{array}{l}\text { Spatial } \\
\text { resolution } \\
\text { [ } \mu \mathrm{m}] \text { or [line } \\
\mathrm{pair} / \mathrm{mm}]\end{array}$ & $\begin{array}{l}8(125 \\
\mathrm{lp} / \mathrm{mm})\end{array}$ & $\begin{array}{l}3,5(142,9 \\
\mathrm{lp} / \mathrm{mm})\end{array}$ & $\begin{array}{l}240(2,2 \\
\mathrm{lp} / \mathrm{mm})\end{array}$ & $\begin{array}{l}18,2 \\
\mathrm{lp} / \mathrm{mm}\end{array}$ \\
\hline
\end{tabular}

From the parameters of selected computed tomographs shown, that the medical tomographs using higher power outputs than the industrial tomographs. The reason is the mineralization of $x$ ray impact into human body. The scanning of human body takes several seconds or minutes. The scanning of selected area of object in industrial tomograph takes for half hour to one hour for 1 Mpix flat panel detector. The spatial resolution is better in industrial tomograps. It is due to the need for detection and evaluation of the level of detail in hundredths of a millimeter. 


\section{Conclusions}

Computed tomography is currently one of the most frequently used diagnostic method, which for obtaining data used X-ray radiation. The radiation transition across the sensing object may produce artifacts that may have a significant impact to the obtained image. In medical viewing artifacts represent wrong displaying of tissue structures in medical images. These artifacts are caused by various phenomena such as physical effect between tissue and energy, error receiving data when patient moving or reconstruction algorithms unable to represent anatomy. It is necessary to recognize these artifacts which can cover or pretend pathological image. For correct interpretation of diagnostic images it is inevitable to understand the principle of particular diagnostic methods and the principle of formation of their artifacts. In the industry the artifacts may prevent evaluation of the porosity of the material and may cause errors in the measurement of dimensions (wrong surface determination in the place of measurement).

\section{Acknowledge}

Presented manuscript was supported by project Research of New Diagnostic Methods in Invasive Implantology, MŠSR-3625/2010-11, Stimuls for Research and Development of Ministry of Education, Science, Research and Sport of the Slovak Republic, the project Center for research of control of technical, environmental and human risks for permanent development of production and products in mechanical engineering (ITMS:26220120060) supported by the Research \& Development Operational Programme funded by the ERDF and project KEGA 036TUKE-4/2013, Implementation of new technologies in design and fabrication of implants in biomedical engineering and related scientific fields.

\section{References}

[1] Živčák, J., Hudák, R., Bednarčḱková, L., Tóth, T., Trebuňová, M.: Biomechanizmy, implantáty na mieru, ISBN: 978-80-553-1396-2, s. 159, 2012

[2] Shampo, M. A., Kyle, R. A. Godfrey Hounsfield-developer of computed tomographic scanning. Mayo Clinic Proceeding, 71(10), p. 990, 1996

[3] Seynaeve, P. C., BROOS, J. I.: The history oftomography. Journal Belgede Radiologie. 78(5), p. 284-288, 1995

[4] Kalender, W. A.: Computed Tomography Fundamentals, System Technology, Image Quality, Applications. Munich: Publicis MCD, 220 p. ISBN 3-89578-081-2, 2000

[5] Reiser, M. F. et al.: Multislice CT. 3rd Ed. Berlin: Springer, 2009, 611 p. ISBN 978-3540-33124-7. s. 5-10, 2009
[6] Fuchs, T., Kachelriess, M., Kalender, W. A.: Technical advances in multislicespiral CT. European Journal Of Radiology, 2000, 36 (2), s. 69-73, 2000

[7] Flohr, T. et al.: First performance evaluation of a dualsource CT (DSCT) system. European Radiology, 16 (2), p. 256-268, 2006

[8] Jhaveri, K., S. et al.: Effect of multislice CT technology on scanner productivity. American Journal of Roentgenology, 177(4),p. 769-772, 2001

[9] Endo, $\mathrm{M}$ et al.: Effect of scattered radiation on imagenoise in conebeam CT. Medical Physics, 28 (4), p. 469-474, 2001

[10] Gupta, R. et al.: Ultra highre solution flat-panel volume CT: fundamental principles, design architecture, and system characterization. European Radiology. 16(6), s.1191-1205, 2005

[11] Barrett, J. F., Keat, N.: Artifacts in CT: Recognition and Avoidance. Radio Graphics, 24 (6), p.1679-1691, 2004

[12] Barrett, J. F. et al.: Cardiac CT scanning. In MHRA Report 03076. [online]. London, England: Medicines and Healthcare Products Regulatory Agency, 2003. 36 p. [cit.2010.06.06] Dostupné na internete: http://www.cep.dh.gov.uk/. ISBN 184182 7460,2003

[13] Seeram, E.:Computed tomography: physical principles, clinical applications and quality control. 2nd ed. Philadelphia, Pa: Saunders, ISBN 9780721681733. p. 174199, 2001

[14] Trebuňová, M, Dankovčik, R., Repovský A. a kol.: Artefakty pri zobrazovaní ultrazvukom, Folia Medica Cassoviensia, in press

[15] Žiičák, J, Trebunoová, M, Repovský, A, Laputková, G.: Artefakty spôsobené pacientom pri zobrazovaní magnetickou rezonanciou. Lékař a technika - Clinician and technology, ISSN 0301-5491, 2(43), s. 17-22, 2013

[16] Živčák, J, Trebuňová, M, Repovský, A, Laputková, G.: Magnetic resonance image artifact due to the examination method and scanning sequences. Acta Mechanica Slovaca, ISSN 1335 - 2393, 17 (3), s.88-92, 2013

[17] Hudák, R., Živčák, J., Magin R.L.: Applications of Metrotomography in Biomedical Engineering In: Biomedical Engineering - Technical Applications in Medicine. - Rijeka : InTech, 2012 P. 225-244. - ISBN 978-953-51-0733-0

[18] Kruth, J.P., Bartscherb, M., Carmignatoc, S., Schmittd, R., De Chiffree, L., Weckenmannf, A.: Computed tomography for dimensional metrology, CIRP Annals - Manufacturing Technology, Volume 60, Issue 2, 2011, Pages 821-842

[19] WeiB, D., Shi Q., Kuhn Ch.: Measuring the 3D resolution of a micro-focus X-ray CT setup, http://www.ndt.net/article/ctc2012/papers/365.pdf

[20] Fedorko, G., Molnár, V., Marasová, D., Grinčová, A., Dovica, M., Živčák, J., Tóth, T., Husáková, N.: Failure analysis of belt conveyor damage caused by the falling material. Part 2: Application of computer metrotomography, In: Engineering failure analysis. Vol. 34 (2013), p. 431-442. - ISSN 1350-6307

[21] Fedorko, G., Molnár, V., Marasová, D., Grinčová, A., Dovica, M., Živčák, J., Tóth, T., Husáková, N.: Failure analysis of belt conveyor damage caused by the falling material. Part 1: Experimental measurements and regression models, In: Engineering failure analysis. Vol. 36 (2014), p. 30-38. - ISSN 1350-6307

[23] http://www.healthcare.siemens.com/

[24] www.gehealthcare.com/ 